\title{
Ideologi Ketaatan terhadap Tuhan/roh dalam Tuturan Ireng pada Guyub Tutur Manggarai
}

\author{
Katarina Noviming Sakura ${ }^{1}$, \\ Flores, NTT-Indonesia \\ e-mail: noviming.sakura@gmail.com \\ I Wayan Simpen ${ }^{2}$, \\ Udayana University, Indonesia \\ e-mail: wyn.simpen@gmail.com \\ I Made Netra $^{3}$ \\ Udayana University, Indonesia \\ e-mail: dektih@yahoo.com
}

\begin{abstract}
Abstrak
Penelitian ini bertujuan untuk mengungkapkan ideologi ketaatan terhadap Tuhan/roh yang ada dalam ireng pada Guyub Tutur Manggarai (GTM). Ireng adalah salah satu bentuk ungkapan larangan yang hidup di Manggarai, diwariskan secara lisan, turun-temurun kepada setiap generasi. Ketaatan terhadap Tuhan/roh yang hendak dicapai melalui ireng didasari pada kepercayaan kuno dinamisme, animisme, dan pengakuan adanya Wujud Tertinggi sebagai Sang Pencipta segala isi bumi.

Masalah yang digali dalam penelitian ini ialah bagaimana ideologi ketaatan terhadap Tuhan/roh diwujudnyatakan dalam ujaran ireng, yang terungkap melalui satuan lingual yang digunakan dan makna yang terkandung di dalamnya. Penelitian ini mengambil beberapa ujaran ireng sebagai data penelitian, yang didapatkan melalui wawancara dan penyebaran kuesioner kepada penutur asli bahasa Manggarai di dua kelurahan di Kabupaten Manggarai. Pengumpulan data dilakukan dengan metode cakap dengan teknik cakap semuka dan tansemuka, teknik rekam, dan teknik catat. Data dianalisis menggunakan metode agih dan metode padan dengan pisau bedah teori Linguistik Kebudayaan. Penyajian analisis data menggunakan metode formal dan informal.

Hasil penelitian menunjukkan adanya penghormatan kepada Tuhan sebagai Wujud Tertinggi dengan adanya ireng atau pengharaman menyebut nama Tuhan dengan tidak hormat misalnya memaki, bersumpah, dan bergurau menggunakan nama Tuhan. Ada juga pemberian nama diri bagi Tuhan yaitu Morin agu Ngaran Bate Jari agu Dedek 'Tuhan Penguasa dan Pemilik alam semesta', Mori Keraeng 'Tuhan', Jari agu Wowo 'Penjadi dan Pembentuk', Jari agu Dading 'Penjadi dan Pelahir'. Adapun penghormatan kepada roh dilakukan melalui beberapa ireng yaitu jangan berteriak saat berada di dalam kebun, dan kewajiban melakukan ritual adat pada ranah pertanian dan perkebunan. Ketaatan terhadap Tuhan/roh bertujuan untuk menjaga relasi baik dengan Tuhan/roh agar GTM memiliki hidup yang aman, tenteram, dan sejahtera.
\end{abstract}

Kata kunci: ireng, ideologi ketaatan, linguistik kebudayaan 


\begin{abstract}
This article aims at describing obedience ideology towards The Lord/spirit that exists in ireng utterances of Manggarai Speech Community. Ireng is one kind of prohibiton in Manggarai, transferred verbally from generation to generation. The obedience towards The Lord/spirit is based on dynamism, animism, and belief in the existence of the Highest being as the Creator of all things in the world.

The problem of this article is how the obedience ideology is described through ireng that could be seen through lingual aspects and its meaning. This article uses some ireng utterances as the data collected by interview and questionnaire from Manggarai language speakers in two districts in Manggarai. The method used is conversation through some technics namely interview face to face, questionnaire, recording, and writing. The data is analized by agih and padan method, using the theory of Cultural Linguistics. Data is presented through formal and informal method.

The result shows that there is ireng or prohibition to use the name of The Lord in inappropriate ways to show respect to being the Highest, such as cussing, swearing, and joking using the name of The Lord. There is also a special naming of The Lord, such as Morin agu Ngaran Bate Jari agu Dedek 'The Lord as the Owner of the world', Mori Keraeng 'The Lord', Jari agu Wowo 'The Maker', and Jari agu Dading 'The Maker of life'. As for the honour to the spirit, it is showed through some ireng, for example not screaming in the garden, and the obligation to perform rituals in farming. The purpose of the obedience to God/spirit is to maintain good relationship with The Lord/spirit in order to have peaceful and prosperous life.
\end{abstract}

Keywords: ireng, obedience ideology, cultural linguistics

\section{Pendahuluan}

Ireng adalah salah satu bentuk ungkapan larangan yang hidup dalam Guyub Tutur Manggarai (GTM). Ireng telah ada dan digunakan sejak zaman nenek moyang Manggarai dan diwariskan turun-temurun kepada setiap generasi. Ireng disebarkan secara lisan dan berlaku bagi semua kalangan usia dan kelompok masyarakat Manggarai. Ireng dapat diartikan sebagai sesuatu yang haram dan tabu.

Sesuatu yang diharamkan atau ditabukan biasanya berkaitan dengan kepercayaankepercayaan tertentu yang hidup dalam suatu masyarakat, begitu pula yang ada dalam ireng. Kepercayaan-kepercayaan yang hidup dalam
GTM membentuk ideologi hidup yang dianutnya untuk mengatur perilaku hidup masyarakat. Salah satu ketaatan yang menjadi ideologi hidup GTM ialah ketaatan terhadap Tuhan/roh.

Ketataan terhadap Tuhan/roh dalam kehidupan Guyub Tutur Manggarai (GTM) didasari pada kepercayaan adanya Wujud Tertinggi dan kepercayaan dinamisme dan amimisme dalam kehidupannya. GTM percaya bahwa ada roh-roh penjaga yang mendiami pohon, mata air, kebun, dan tempat-tempat tertentu lainnya. Di atas semua itu, GTM percaya adanya kekuatan yang tidak dapat dijelaskan yang menciptakan nenek moyang mereka dan seisi bumi ini. 


\section{Metode Penelitian}

Penelitian ini dilakukan di Kelurahan Golo Dukal dan Compang Tuke, Kecamatan Langke Rembong, Kabupaten Manggarai. Pemilihan Kabupaten Manggarai sebagai lokasi penelitian dikarenakan bahasa Manggarai yang digunakan merupakan bahasa Manggarai standar atau baku. Sumber data pada penelitian ini ialah tuturan (tradisi lisan). Data dibedakan atas data tulis dan data lisan. Data lisan didapatkan dari hasil wawancara dengan informan terpilih penutur bahasa Manggarai, sedangkan data tulis didapatkan dari hasil kuesioner kepada penutur bahasa Manggarai.

Metode pengumpulan data yang digunakan adalah metode cakap dengan teknik cakap semuka, cakap tansemuka, teknik rekam, dan teknik catat. Disebut metode cakap atau percakapan karena berupa percakapan dan terjadi kontak antara peneliti dengan pelaku sebagai narasumber (Sudaryanto, 2015: 208). Data yang telah terkumpul selanjutnya dianalisis menggunakan metode agih dan metode padan.

Pada metode agih, alat penentunya adalah bagian dari bahasa itu sendiri. Teknik Bagi Unsur Langsung (BUL) digunakan pada metode agih pada penelitian ini. Teknik BUL dilakukan dengan membagi satuan lingual data menjadi beberapa bagian atau unsur dan unsur-unsur tersebut dipandang sebagai bagian yang langsung membentuk satuan lingual yang dimaksud. Alat penggerak atau daya bagi pada teknik ini ialah intuisi kebahasaan peneliti, dan alat penentunya adalah jeda baik yang silabik maupun sintaktik (Sudaryanto, 2015: 37). Berbeda dengan metode agih, penentu metode padan berada di luar, terlepas, dan tidak menjadi bagian dari bahasa yang diteliti (Sudaryanto, 2015: 15). Pada metode padan, analisis data menggunakan teknik pilah bagi unsur penentu (PUP) dengan daya pilah referensial dan pragmatis. Metode padan referensial memiliki alat penentu kenyataan yang ditunjuk atau diacu oleh bahasa, sedangkan pada padan pragmatis alat penentunya ialah mitra wicara.

Teori yang digunakan untuk menganalisis data adalah teori Linguistik Kebudayaan yang dikembangkan oleh Palmer. Teori ini mencakup gramatika bahasa, etnosemantik, dan etnografi berbicara. Palmer menyatakan bahwa bahasa adalah permainan simbol verbal yang berbasis pada imajeri. Imajeri adalah apa yang dibayangkan, apa yang dirasakan, dan apa yang dipikirkan. Dalam mengembangkan Linguistik Kebudayaan, Palmer juga menegaskan bahwa Linguistik Kebudayaan terutama berurusan bukan pada bagaimana orang berbicara tentang realitas objektif, melainkan pada bagaimana orang-orang itu berbicara tentang dunia yang mereka sendiri bayangkan (Erom, 2007: 1,23). Hal ini selaras dengan konsep ireng yang memuat banyak imajeri dalam pengungkapannya dan imajeri ini terus hidup.

Penyajian analisis data dilakukan dengan metode formal dan informal. Metode penyajian informal adalah perumusan dengan kata-kata biasa, sedangkan penyajian formal adalah perumusan dengan tanda dan lambang-lambang (Sudaryanto, 2015: 241).

\section{Hasil dan Pembahasan}

Ideologi ketaatan terhadap Tuhan/roh yang diungkapkan dalam tuturan ireng pada GTM menyatakan adanya relasi yang ingin dijaga turun-temurun. Sebagai Wujud Tertinggi, Tuhanlah yang Empunya nafas kehidupan segala makhluk di bumi dan Empunya segala isi bumi. Adapun ketaatan terhadap roh menunjukkan adanya relasi yang ingin dijaga, sebab roh-roh tak kelihatan diyakini juga hidup bersama manusia di bumi dan menggunakan isi bumi bersama manusia. Berikut ini penjabaran tiap bentuk ketaatan yang ditemukan.

\subsection{Ideologi ketaatan terhadap Tuhan}


Sebagai Wujud Tertinggi, Sang Penguasa kehidupan, Tuhan layak mendapatkan penghormatan dari semua umat manusia. Di Manggarai, Tuhan memiliki beberapa nama diri, misalnya Morin agu Ngaran Bate Jari agu Dedek 'Tuhan Penguasa dan Pemilik alam semesta', Mori Keraeng 'Tuhan', Jari agu Wowo 'Penjadi dan Pembentuk', Jari agu Dading 'Penjadi dan Pelahir', dan sebagainya. Mori Keraeng adalah nama diri bagi Tuhan yang sering digunakan oleh GTM. Data ujaran ireng yang menyatakan ideologi ketaatan terhadap Tuhan ialah sebagai berikut.

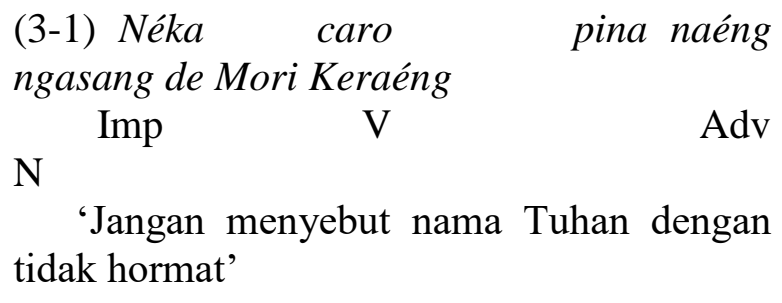

Ireng (3-1) merupakan kalimat imperatif yang ditandai dengan kata larang neka 'jangan' sebagai kata imperatif untuk melarang. Ireng ini berlaku bagi semua GTM, dari yang tertua hingga yang termuda. Tujuan ireng ini adalah untuk menghormati nama Tuhan yang kudus. Pengharaman menyebut nama Tuhan dengan tidak hormat pada ireng ini dinyatakan secara langsung, tegas, dan tanpa maksud tersembunyi. Hal ini, terlihat dari pilihan kata yang digunakan, yang memiliki maksud harafiah tanpa menutupi maksud yang sebenarnya. Tidak juga disisipi permintaan maaf atau permisi untuk menegur.

Penutur dan petutur sudah saling memahami konteks ujaran ireng ini, yaitu Tuhan sebagai Wujud Tertinggi wajib dihormati oleh semua manusia. Ketika seorang penutur mengucapkan ireng ini, tidak ada pertanyaan lanjutan dari petutur, misalnya menanyakan alasan larangan tersebut. Dengan kata lain, imajeri GTM tentang Tuhan Sang Pencipta alam semesta, Tuhan yang Mahabesar, Tuhan yang menciptakan manusia, melekat kuat dalam pikiran dan gambaran GTM tentang siapa Tuhan dan bagaimana peranNya dalam kehidupan.

Adanya beberapa nama diri bagi Tuhan juga menyiratkan bentuk penghormatan dari GTM. Ireng ini tidak hanya benar secara adat, tetapi juga dari segi pendidikan agama. Jangan menyebut nama Tuhan secara sembarangan adalah salah satu butir 10 Perintah Allah dalam ajaran Gereja Katolik, sebagai agama mayoritas yang dianut oleh GTM. Yang termasuk dalam menyebut nama Tuhan dengan tidak hormat ialah ketika seseorang menyumpah, memaki, dan bergurau menggunakan nama Tuhan.

\subsection{Ideologi ketaatan terhadap roh}

Guyub tutur Manggarai pada masa kuno menganut kepercayaan dinamisme dan animisme, yaitu percaya pada roh-roh halus. Mereka berkeyakinan bahwa kebanyakan roh (dewa/leluhur) hadir pada pohon-pohon besar, dan di sumber mata air/rawa-rawa. Pohon dan tempat-tempat tersebut dianggap keramat, yang mempunyai kekuatan dan perlindungan (Nggoro, 2016: 11-12). Oleh karena itu, GTM berhati-hati dalam bertutur dan bertindak pada tempat-tempat tersebut. Beberapa ireng yang mengungkapkan ideologi ketaatn terhadap roh dapat dilihat di bawah ini.

$\begin{array}{ccc}\text { (3-2) Néka } & \text { ciék } & \text { oné uma } \\ \text { Imp } & \mathrm{V} & \text { Dk.lok }\end{array}$
kebun'

'Jangan berteriak saat berada di dalam Salah satu tempat yang dianggap keramat ialah kebun, seperti pada ireng (3-2) di atas. GTM percaya ada roh penjaga kebun yang mendiami 
tempat tertentu di dalam kebun. Berteriak dalam KBBI dikatakan sebagai seruan yang keras; pekik. Dengan begitu, sudah tergambarkan bagaimana roh penjaga akan merasa terganggu dengan seruan yang keras di dalam lingkungan tempat tinggalnya. Berteriak dalam konteks ireng ini meliputi berteriak membuat keributan dan berteriak saling memanggil satu sama lain.

Ireng ini berlaku terutama bagi anak-anak dan remaja. Orang dewasa yang mengetahui ada anak atau remaja yang berteriak di kebun akan langsung menegurnya. Konsekuensi dari pelanggaran ireng ini ialah mengalami gangguan mental, terkena sakit penyakit, dan bahkan menghilang dari kebun. Untuk menghindari hal ini, biasanya orang dewasa akan memperingatkan anak-anaknya sebelum berangkat ke kebun.

Unsur lingual ujaran ireng ini yang menyasar pada ketaatan ialah penggunaan kata neka 'jangan' dan langsung diikuti oleh hal yang dilarang. Tidak ada maksud tersembunyi, juga tidak ada basa-basi untuk kesopanan. Alasan pelarangannya memang tidak disebutkan, tetapi karena sudah diperingatkan sejak sebelum berangkat ke kebun, para pelaku tindakan tersebut akan langsung diam ketika ditegur. Imaji tentang roh penjaga dan konsekuensinya membuat para pelaku taat dan bahkan merasa ketakutan.

(3-3) Latung ngoél, woja weru, ai du wangka weri, weri latung, weri woja,

V

$$
\begin{array}{lll}
\mathrm{N} & \mathrm{N} & \text { Dk.waktu }
\end{array}
$$

pandé manuk dara, boto towak wa tanas latung agu woja

$\operatorname{Imp}$

Adv

'Ritual adat harus dilakukan sejak awal menanam bibit jagung dan padi, agar bibit tersebut tidak membusuk di dalam tanah'
(3-4) Jari kolé latung agu woja, toé rodo hangs, V N Imp woja weru.

olong pandé manuk hang latung weru agu V

'Saat memanen jagung dan padi, terlebih dahulu harus melakukan ritual adat makan jagung baru dan padi baru'

Ireng (3-3) dan (3-4) menyatakan peraturan dalam berkebun, yaitu harus ada ritual adat sebelum menanami kebun dan ritual adat saat memanen hasil kebun. Kedua ireng ini merupakan perintah yang disampaikan dengan cara menasihati. Tidak ada kata imperatif neka 'jangan' di dalamnya, tetapi ada bentuk imperatif lain. Pada (3-3), bentuk imperatif ditandai dengan frasa verba pandé manuk dara 'lakukan ritual adat' yang diikuti dengan frasa adverbia boto towak wa tanas latung agu woja 'awas bibit jagung dan padi membusuk di dalam tanah' sebagai penegasan akibat pelanggaran. Adapun pada (3-4) bentuk imperatif dinyatakan melalui toé rodo hangs 'tidak bisa langsung dimakan' dan ditegaskan lagi pada klausa berikutnya olong pandé manuk hang latung weru agu woja weru 'harus terlebih dahulu melakukan ritual adat makan jagung baru dan padi baru'.

Terkait dengan kepercayaan dinamisme dan animisme yang dianut oleh nenek moyangnya, pemujaan terhadap dewi tanah dan penjaga mata air masih dilakukan hingga kini seperti pada ritual membuka kebun baru, menanami kebun, memanen, ritual, ritual pergantian tahun, dan lain-lain Ireng (3-3) dan (3-4) juga masih ditaati hingga kini, sebagai bentuk pemujaan terhadap dewi tanah. Konsekuensi pelanggaran ireng tersebut ialah sakit perut dan hasil kebun habis dimakan tikus. 


\section{Simpulan}

Dari penjabaran beberapa ireng di atas, dapat disimpulkan bahwa ireng bertujuan untuk menghindarkan GTM dari segala sesuatu yang buruk dan tidak diinginkan. GTM ingin hidup aman, tenteram, dan sejahtera. Hal-hal yang dilarang mengacu pada perbuatan yang tidak pantas dilakukan, dan yang tidak akan mendatangkan ketenteraman hidup. Ireng tidak pandang bulu, setiap lapisan masyarakat GTM harus menaatinya.

GTM mengakui adanya Tuhan sebagai Wujud Tertinggi dalam kehidupan dan adanya dunia lain yang juga hidup bersama. Sebagai Sang Pencipta, Penguasa langit, dan bumi, Tuhan mendapatkan penghormatan di tempat pertama. Adapun roh, dipercaya hidup bersama manusia di bumi sehingga harus diberi ruang gerak sendiri. Peran Tuhan dan roh yang berbeda-beda itu, menyebabkan adanya porsi yang berbeda juga dalam hidup GTM, terutama dalam budayanya. Ideologi ketaatan terhadap Tuhan/roh didasari atas peran yang berbeda-beda itu, sehingga jika tidak ditaati maka akan menimbulkan kerugian bagi para pelanggarnya

\section{Daftar Pustaka}

Hemo, Doroteus. 1988. Sejarah Daerah Manggarai.

Mbete, Aron Meko. 2013. Sekilas tentang Linguistik Kebudayaan. Bahan Matrikulasi Program Magister Linguistik Universitas Udayana.

Nggoro, Adi M. 2016. Budaya Manggarai Selayang Pandang. Yogyakarta: Moya Zam-Zam Printika.

Palmer, Gary B. 1996. Teori Linguistik Kebudayaan. (Diterjemahkan oleh Erom, Kletus) Denpasar: Universitas Udayana.
Sibarani, Robert. 2004. Antropolinguistik. Medan: Penerbit Poda.

Sudaryanto. 2015. Metode dan Aneka Teknik Analisis Bahasa. Yogyakarta: Sanata Dharma University Press.

Tim Penyusun. 2011. Gereja Menyapa Manggarai. Manggarai: Yayasan Theresia Pora Plate

KBBI online diakses pada 01 Oktober 2019 